\title{
Hover In-Ground-Effect Testing of a Full-Scale, Tilt-Nacelle V/STOL Model
}

\author{
James E. Eshleman, Michael R. Dudley, and \\ Charles J. Schell
}

February 1986

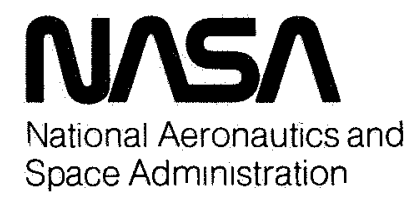


NASA Technical Memorandum 88218

\section{Hover In-Ground-Effect Testing of a Full-Scale, Tilt-Nacelle V/STOL Model}

James E Eshleman,

Michael R Dudley, Ames Research Center, Moffett Field, California

Charles J. Schell, Grumman Aerospace Corporation, Bethpage, New York

February 1986

\section{N/Sก}

National Aeronautics and

Space Admınıstration

Ames Research Center

Moffett Field. Californı 94035 
HOVER IN-GROUND-EFFECT TESTING OF A FULL-SCALE, TILT-NACELLE V/STOL MODEL

James E. Eshleman* and Michael R Dudley*

NASA Ames Research Center, Moffett Field, California

Charles J Schell ${ }^{\dagger}$

Grumman Aerospace Corporation, Bethpage, New York

\section{Abstract}

A full-scale, tilt-nacelle V/STOL aircraft model was tested in hover at the National Full Scale Aerodynamics Complex (NFAC), NASA Ames Research Center The model of Grumman Aircraft Corporation's design 698 was powered by two General Electric TF-34 turbofan engines. It was tested at several ground heights and control deflections. Test technique and test setup were documented Limited results show that 1) a small change in control power with ground height was measured, and control power was found to be good over $\pm 20^{\circ}$ of horizontal-vane deflection;

2) integrated fuselage undersurface pressures, when compared with the total model loads and measured thrust, defined the effect of the fountain and its related flow field on model forces and moments, and 3) there was no indication of hot-gas ingestion during simulated takeoff in calm winds from wheels on deck ground height

\section{Nomenclature}



$h / D$ nondimensional model height, measured from fuselage underside

\footnotetext{
*Aerospace Research Engineer Member AIAA

$t_{\text {Propulsion Eng ineering Specialist }}$

This paper is declared a work of the U.S. Government and therefore is in the public domain.
}

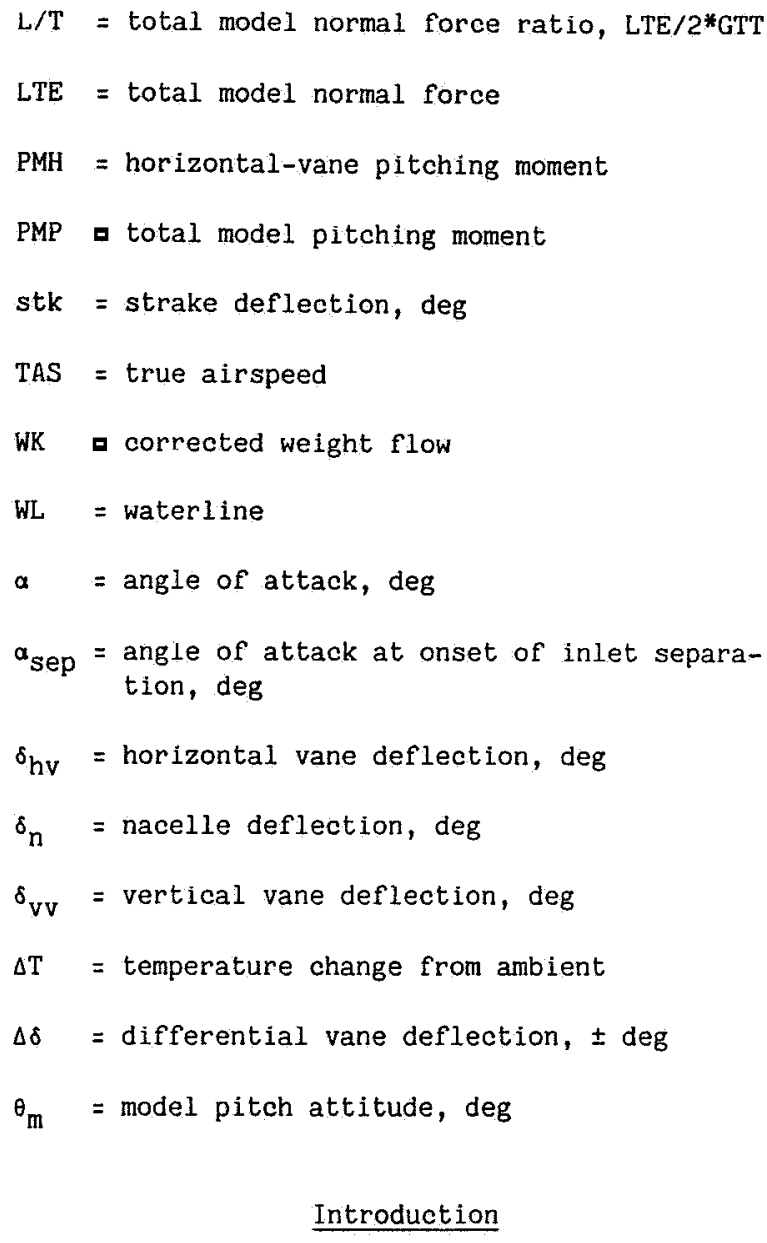

\section{Introduction}

Current interest in the development of vertical and short takeoff and landing (V/STOL) aircraft has primarily been driven by the military need for aircraft capable of operating from small surface vessels, damaged runways, and austere sites This need includes operation on large aircraft carriers while the carriers' main runways are being used by conventional fixed-wing aircraft There may also be potential civilian uses in the remote northern latitudes where considerable effort is spent keeping the few available runways open for conventional aircraft and where the large expanses to be traversed make rotorcraft impractical. These and other uses are reviewed in Ref 1 , which includes summaries of wind-tunnel and flight-test results for three types of V/STOL aircraft One of these was the tilt-nacelle design which would be capable of operating at speeds and altitudes well above those of many existing advanced rotorcraft and turboprop 
aircraft. The twin tilt-nacelle design is the subject of this investigation.

The tilt-nacelle aircraft is powered by two high-bypass-ratio turbofan engines mounted on a single carry-through structure (this entire assembly is referred to as a "dumbbell") The dumbbell assembly allows the thrust vector of the tilt-fan to be rotated from the horizontal to the vertical while maintaining the thrust vector close to the center of gravity; as a result, only small trim and control forces are required During hover and transition to wing-borne flight, these trim and control forces are provided by a set of control vanes immersed in the engine exhaust A fullscale powered model of this concept has been designed and fabricated under a joint effort by the Ames Research Center, the Navy, and Grumman Aerospace Corporation (GAC) The configuration, designated design 698 , was extensively tested in the $40-$ by $80-\mathrm{ft}$ wind tunnel and at the Outdoor Aerodynamic Research Facility (OARF) These facilities, along with the $80-$ by $120-\mathrm{ft}$ wind tunnel, constitute the National Full Scale Aerodynamics Complex (NFAC) at Ames Research Center Results of these previous tests are discussed in Refs. 2-4

The subjects of this paper are test technique, test setup, and evaluation of limited results of the hover test conducted from May to September, 1983, at the OARF Objectives of this test include evaluation of control effectiveness, inlet hot-gas ingestion, and performance of variable-geometry fuselage strakes during hover in close proximity to the ground. The previous test envelopes were expanded to include operation at high power--thrust of $40,000 \mathrm{~N}(9,000 \mathrm{lb})$ per engine--and at ground heights equivalent to wheels-on-deck

\section{Model Description}

\section{Basic Airframe}

The general geometry of the model is shown in Fig 1 More detailed model geometry and fabrication data can be found in Ref 2 (pp. 27-35) The basic airframe, designed by GAC and built by NASA, includes the fuselage, wing, empennage, and support struts. The fuselage volume houses the nacelle actuators and major instrumentation. The empennage consists of a fixed vertical stabilizer and an all-movable horizontal tail The $11.2-\mathrm{m}-$ span gull wing had a $75^{\circ}$ forward-swept leading edge and a trailing-edge flap fixed at a $5^{\circ}$ deflection Longitudinal strakes, designed to house conformal radar, as well as enhance lift in ground effect, were installed on each side of the fuselage. These strakes consisted of four individually adjustable panels that could be set to deflections of $8^{\circ}, 30^{\circ}, 45^{\circ}$, and $70^{\circ}$ It should be noted that in the previous references, strake angle was referred to the chordline of the strake, here, it is referred to the lower surface of the strake (for example, the $15^{\circ}$ strake angle used in Refs $2-4$ would correspond to the $8^{\circ}$ strake angle here). Several runs were made with fore and aft panels removed to evaluate the effectiveness of shortened strakes. See Fig. 1 (also Fig 10) for strake geometry

\section{Dumbbell Assembly}

The dumbbell assembly (Fig. 2), designed and built by GAC, consisted of two General Electric $\mathrm{TF}-34-100$ turbofan engine and nacelles mounted to a cross-box assembly that pivoted from the fuselage just forward of the wing Control of the nacelle incidence angle was provided by two actuators located in the fuselage During hover and transition, aircraft control is obtained by deflecting control vanes immersed in the exhaust of each engine (Fig, 3) These control vanes consist of a horizontal vane with a $30 \%$ chord trailing-edge flap and two vertical control vanes, which were pivoted from the horizontal vane at its one-quarter chord The entire vane assembly is supported from the dumbbell by a boom located immediately inboard of each engine nacelle Actuators for the control vanes were located within this boom.

While hovering, pitch and yaw are controlled by symmetric and differential deflection of the horizontal vanes Nacelle tilt could also be used to augment pitch control Roll control is provided by differential thrust (by manipulating the throttle and inlet guide vanes), and by deflecting the vertical vanes The vertical vanes can also be used for thrust modulation. To provide pitch or roll moments, the control vanes produce forces perpendicular to the engine axis at a substantial distance below the aircraft mass center since these moments are produced by a single unopposed force opposite to the desired direction of travel, a "negative" acceleration is the first result of the pilot input. References 5 and 6 discuss this so-called "adverse nonminimal phase" and other control features, as well as handling qualities, for the tilt-nacelle configuration

During the transition to wing-borne flight, the engine nacelles must operate at extreme angles of attack To prevent inlet flow distortion and separation, the TF-34s were equipped with specially designed asymmetric inlets Typical inlet separation boundaries, as reported in Ref 1, are shown in Fig 4 Reference 7 discusses some of the design considerations for such an inlet

\section{Engine Modifications}

The standard TF-34-100 engine can be operated vertically for only about $45 \mathrm{sec}$ without incurring damage resulting from lack of oil or from inadequate oil scavenge Since this is not long enough to permit ground testing or actual aircraft operation, the lubrication systems of the TF-34s were modified by General Electric (under a NASA-Navy contract) to provide adequate lubrication during 
operation at all nacelle attitudes to be tested $\left(0^{\circ}\right.$ to $\left.90^{\circ}\right)$ Figure 5 illustrates the standard TF-34 lubrication system as well as the modifications. Much of the standard lubrication system, not affected by the modification, has been simplified for clarity Consequently, this figure should not be considered an accurate representation of the entire lubrication system. These modifications included addition of two slave tanks, a gearbox collector tank, and several gearbox scavenge lines. An elbow was installed within the main tank to improve oil supply to the feed pump while in the vertical attitude Oil sumps $A$, $B$, and $C$ were also modified Further details of the lubrication-system modifications can be found in the Appendix With these modifications, the engines could be run at nacelle angles of $90^{\circ}$ for periods in excess of 90 min at maximum continuous power or for $20 \mathrm{~min}$ at military power

\section{Model Setup}

The entire model was mounted on three struts above a 42 -ft long by 36 -ft wide ground plane Figure 6 shows the installation at the OARF Model height above the ground plane was set by the installation or removal of various fixed-length sections of the main-support struts Model pitch attitude was set by remote height adjustment of the telescopic tail strut Total model forces and moments were measured by $40-$ by $80-\mathrm{ft}$ wind-tunnel three-component load cells mounted at each model attachment point Relative sideways motion between the model and left strut was restrained, with the right load cell being allowed to slide on its mounting pin to allow for model growth and support-strut deformation

Load-cell force measurements are corrected for misalignments greater than $01^{\circ}$, for interactions owing to loads normal to the gauged axis, and for thermal effects. A detailed discussion of model installation and of three-component loadcell measurement techniques can be found in Ref 8 Each main load cell was thermally compensated; however, cooling cans were installed over each to prevent direct impingement of the hot exhaust gases. Considerable effort was made to prevent impingement of the fountain gases on the tail-strut load cell This consisted of shielding the entire tail-strut system and installing several additional cooling air lines. In spite of these measures, tail-strut load-cell temperatures of ten exceeded $66^{\circ} \mathrm{C}\left(150^{\circ} \mathrm{F}\right)$ The effect of this temperature on the tall-strut normal force was large enough to require correction through calibration (Fig 7), even though the gauge was equipped with thermal compensation

During testing at low ground heights, the model was observed to oscillate in at least two modes: a yaw mode and a side-to-side translation mode, both with a period of about $10 \mathrm{sec}$ Excited by any disturbance that loaded the model asymmetrically, these oscillations resulted in a sinusoidal output from the main load cells being superimposed over the steady-state value. Since the data were averaged over more than $7 \mathrm{sec}$, this oscillation does not appear in the results Also, the magnitude of the total model motion was only about $1 \mathrm{~cm}(0.5 \mathrm{in})$, so any influence of this motion on the aerodynamic loads is believed to be negligible

It should be noted that there is a distinct trade-off between rigidity (strut size) and interference effects owing to the presence of the model support system in the flow field below the model To prevent this problem, as well as the heating problem noted earlier, it is recommended that future large-scale powered models be mounted from an overhead support system for hover testing

\section{Model Instrumentation}

Figure 8 illustrates the model instrumentation layout. The dumbell assembly was instrumented to measure overall forces and moments, gross thrust, control-vane loads, engine condition, and flow distortion. A seven-element strain-gauge balance incorporated in the dumbbell assembly allowed measurement of the total thrust of the propulsion system. The forces and moments measured from the dumbbell balance were measured in a reference frame that rotated with the nacelle Control-vane loads were measured by 10 strain-gauge eircuits installed within the left vane assembly Total pressure, static pressure, and total temperature rakes were used to measure momentum thrust, mass flows, bypass ratio, and inlet distortion of the left engine Figure 9 shows the locations of these rakes within the engine and also shows details of a typical rake assembly Thermocouples were installed within both engines to monitor engine condition and lubrication-system performance. Standard aircraft-type analog engine instrumentation was used for engine operation and monitoring.

The instrumentation layout for the fuselage underside is shown in Fig 10 all 119 pressure taps installed on the underside of the fuselage were measured using Scanivalve pressure transducer modules Thirteen of these taps were manifolded to both scanivalve and discrete pressure transducers to determine time-varying characteristics of the upwash fountain. The integrated pressure load was assumed to reflect forces and moments induced on the underside of the aircraft Eighteen static temperature thermocouples were also installed on the fuselage underside These thermocouples were fabricated so as to measure static air temperature, not skin temperature

As mentioned earlier, the total model forces and moments were measured by three $40-$ by $80-\mathrm{ft}$ wind-tunnel, three-component load cells These load cells can measure normal forces to $\pm 18,000 \mathrm{lb}$, axial forces to $\pm 6,000 \mathrm{lb}$, and side forces to $\pm 2,000 \mathrm{lb}$

The ground plane was instrumented with 107 static pressure taps and 23 thermocouple 
ports. These thermocouples were similar in construction to those used on the fuselage underside. Total-pressure and total-temperature rakes were also installed on the ground plane to measure the wall-jet profile The instrumentation layout for the ground plane and the wall-jet rake details are shown in Fig 11

\section{Data Acquisition}

The OARF data-acquisition system consists of a PDP 11/70 computer, PDP 11/04 Kernal system, and two Teledyne RMDU control units (RCU) All bridge circuits contain precision calibration resistors (Real) in a six-wire system with individual leads to the remote calibration resistor The vast majority of the pressure data was acquired by 48-port scanivalves Calibration resistors were not used on the scanivalve transducer; instead, a known calibration pressure (Pcal) and an atmospheric reference were applied to two ports of each scanivalve. Non-scanivalve data channels were sampled 600 times over a 7,68-sec interval Each scanivalve channel was sampled 60 times over a $0.768-\mathrm{sec}$ interval Each scanivalve sampling interval was preceded by a 400 -msec settling period (critical reference channels were allowed $750 \mathrm{msec}$ )

\section{Data Uncertainty}

Data uncertainty resulting from transducer nonlinearity, analog-to-digital conversion errors, amplification nonlinearity, and power-supply drift were kept within $0.2 \%$ of the maximum measured values, other sources of uncertainty resulted from errors in the experimental setup and procedures, simplifying assumptions, and oscillating loads

Before any critical data were taken, as well as during the test, known loads were applied to each load-measuring system to demonstrate 1 inearity and to expose any possible metric-nonmetric fouling problems Figures 12 and 13 illustrate typical load-measuring verification results. The curves are very linear, smooth, and show no hysteresis It should be noted that these pulls were conducted in calm weather with a steady load applied to each gauged axis separately; thus, these data represent the best that can be expected from the model in its current configuration In general, the load-cell data are reliable to within $2 \%$ of the applied load for the normal and axial components and $5 \%$ for the side component

Similar results can be demonstrated for the pressure instrumentation However, since scanivalve data were recorded sequentially over a significant period of time ( $55 \mathrm{sec})$, any lowfrequency dynamic effects could produce additional errors This possibility is discussed further in the next section (Analysis of Results)

\section{Test Envelope}

A major objective of this test was expansion of the existing data base as reported in Refs. 2-4. Consequently, limited runs overlapping the previous hover test envelope were included for data verification and completeness. The test matrix consisted of the following:

$$
\begin{aligned}
&(72 \text { in. }) \\
& h / D= 10,139,2.0 \\
& \mathrm{~F}_{\mathrm{g}}= 0 \text { to } 80,000 \mathrm{~N}(18,000 \mathrm{lb}) \\
& \theta_{\mathrm{m}}=-5^{\circ} \text { and } 0^{\circ} \\
& \delta_{\mathrm{stk}}=8^{\circ}, 30^{\circ}, 45^{\circ}, \text { and } 70^{\circ} \\
& \delta_{\mathrm{n}}=5^{\circ} \text { to } 90^{\circ} \\
& \delta_{\mathrm{hv}}=+25^{\circ} \text { to }-25^{\circ} \\
& \Delta \delta_{\mathrm{hv}}= \pm 25^{\circ} \text { to } 725^{\circ} \\
& \delta_{\mathrm{vv}}=+25^{\circ} \text { to }-25^{\circ}
\end{aligned}
$$$$
\mathrm{h}=0.95 \mathrm{~m}(37 \mathrm{in}), 1.2 \mathrm{~m}(50 \mathrm{in}), \text { and } 1.8 \mathrm{~m}
$$

Limited running was conducted at $\delta_{v v}$ a $35^{\circ}, 50^{\circ}$, and $70^{\circ}$ to evaluate the effectiveness of the vertical vanes as a thrust-spoiling device Combined horizontal- and vertical-vane deflections were also tested to evaluate their interactions. At $\mathrm{h} / \mathrm{D}=10$, a simulated takeoff was conducted to evaluate any dynamic effects on inlet hot-gas ingestion

\section{Operational Considerations}

Several series of power-off tare runs were required to remove the effects of nacelle position, model attitude, and control-vane configuration on the forces and moments being measured These tare runs consisted of nacelle sweeps at model attitudes of $-5^{\circ}$ and $0^{\circ}$ Control-vane sweeps were made at various points during the nacelle sweep This allowed a full complement of weight tare data to be taken, for the vanes, from orientations of $-25^{\circ}$ to $+115^{\circ}$ relative to the horizontal. Figure 14 shows the effect of nacelle angle on total model pitching moment In Fig 15, some typical vane tare data illustrate the effects of nacelle angle and of horizontal-vane deflection on control-vane normal force measurements

To allow adequate data-acquisition time, the 5-min limit for operation between intermediate and maximum thrust (low-pressure turbine inlet temperatures between $776^{\circ} \mathrm{C}$ and $827^{\circ} \mathrm{C}$ ) was extended to $20 \mathrm{~min}$.

The test was conducted outdoors, and the model, of course, was subjected to ambient weather conditions. Most data acquisition was made in winds of less than 5 knots 


\section{Analysis of Results}

Figure 16 shows the effects of ground height and horizontal-vane deflection, as defined in Fig. 3, on the total model pitching moment. The horizontal vanes maintained linear control power over $\pm 20^{\circ}$ of deflection down to a ground height of $h / D=139$. At the lowest ground height $(h / D=1.0)$ corresponding to wheels-on-deck height there was a $5^{\circ}$ negative shift in vane angle for the same pitching moment and a slight reduction in the amount of control power available

The $5^{\circ}$ shift is likely a result of curvature of the exhaust jet as it impinges on the ground plane. Since the horizontal control vane is offset from the jet centerline, this curvature produces an effective angle of attack on the vane Since this shift was observed only at the lowest ground height ( $h / D=1.0$, wheels on deck, as measured from the fuselage undersurface), it is probably not a significant factor in the handling qualities of the aircraft

The reduction in control power available at an $h / D$ of 10 (Fig 16) for control deflections greater than approximately $10^{\circ}$ is probably caused by flow separation at high positive vane deflections. The degradation is also observed at high negative deflections, and it is unlcear whether it is due to flow separation or to the vane approaching the jet boundary These characteristics also disappear at $h / D=139$.

There is also a noticeable effect of strake position on control-vane effectiveness (Fig 17) Since the strake angle has no effect on the engine exhaust flow field in the vicinity of the control vanes, this shift cannot be due to a change in the loads on the vanes themselves To understand this effect, it is important to remember that the total model pitching moment is the result of loads on the control vanes, as well as a result of distributed pressure forces on the model It will be shown later that the major source of these pressure-induced forces is the impingement of the upwash fountain on the undersurface of the fuselage. Both the control vanes and strakes have a noticeable effect on the fountain-induced loads Consequently, it is believed that the change in control-vane effectivensss results from changes in the pressure-induced loads on the underside of the fuselage

Figure 18 illustrates the strong effect of strake configuration on the total model normal force in ground effect. The decrease in total model normal force at $h / D=1.0$ ground height is of particular interest. This effect is thought to be due to a pair of longitudinal vortex-like flows that are observed to form on the fuselage undersurface along either side of the fountain As the height above the ground is reduced, both fountain and vortex strength increase However, the increase in vortex strength apparently dominates at the lowest height, resulting in a reduction of total model normal force. This phenomenon has been demonstrated in small-scale tests conducted by Hall and Rogers. 9

As mentioned earlier, the ground-effect cushion is demonstrated to be due primarily to the forces acting on the fuselage undersurface Figure 19 compares the total model normal force and the sum of total engine thrust as measured by the dumbbell balance, and fuselage undersurface normal force obtained by integrating the pressures on the fuselage undersurface. Virtually all of the additional lift increment in ground effect is caused by loads on the fuselage undersurface.

It is important to notice the large data scatter on these curves From the calibration data it is clear that total model loads should be measurable well within this scatter band The fact that there is very little variation in the thrust levels at these conditions suggests that the scatter comes from another source. Figure 19 shows that the amount of scatter present in the integrated fuselage loads is approximately equal to the scatter in the total model loads Considering the dynamic nature of the fountain and its possible susceptibility to outside disturbances such as ambient winds, it is probable that the major source of scatter in these measurements is low-frequency flow oscillation under the model There may also be an averaging effect as a result of the significant sampling time required by the scanivalve instrumentation

To simulate the dynamies involved with vertical takeoff, the engines were rotated to the vertical attitude at approximately $80 \%$ core speed $(14,000 \mathrm{rpm})$ Both throttles were then advanced as rapidly as possible to full military power (approximately $3 \mathrm{sec}$ ) During this time and for several seconds after reaching full military power, the fan inlet temperatures were monitored by high-speed oscillographic recorders There was no evidence from the fan inlet temperature measurements of hot-gas ingestion steady-state smoke visualization studies verified that there was no reingestion

\section{Concluding Remarks}

A full-scale powered model of the Grumman Aerospace Corporation design 698 twin tilt-nacelle V/STOL was tested, and the test technique and test setup were documented Limited analysis of the results indicates the following:

1) A small change in control power with ground height was measured. Control power was found to be good over $\pm 20^{\circ}$ of horizontal-vane deflection

2) Comparison of integrated fuselage undersurface pressures with the total model loads and measured thrust indicates that the primary groundeffect mechanism is the fountain and its related flow field 
3) There was no indication of hot-gas ingestion during simulated takeof in calm winds from a wheels-on-deck ground height

\section{Appendix: TF-34-100 Lubrication System Modifications}

Modifications to the TF-34-100 engine lubrication system consisted of several relatively small changes to most of the system components These modifications included addition of two slave tanks, a gearbox collector tank, and several gearbox scavenge lines. An elbow was installed within the main oil tank to improve oil supply to the feed pump while at vertical attitude. oil sumps $A, B$, and $C$ (Fig, 4) were also modified to allow better oil scavenge while operating near the vertical attitude

The two new slave tanks were located just forward of the gearbox (Fig 20). The larger tank (3. 70 liters) was located on the left side of the engine and the smaller ( 183 liters) on the right. During typical operation, the engines were held at approximately $60^{\circ}$ nacelle deflection and $80 \%$ core speed $(14,000 \mathrm{rpm})$ for $2 \mathrm{~min}$, allowing oil to transfer from the slave tanks to the main tank before operating at higher nacelle angles

Because of the shape of the gearbox, considerable amounts of oil could collect when the nacelles are vertical To prevent this, four scavenge lines were added to the gearbox at what would be critical low spots in the vertical attitude. Drainage holes were opened at various points to facilitate the flow of oil to these low spots The collector tank was mounted from the gearbox hydraulic pump pad This tank served as a scavenge port, as well as a collector for the scavenge lines

The forward A-sump scavenge line was removed and the forward A-sump scavenge pump was plumbed to the bottom of the gearbox collector tank (removal of the forward A-sump scavenge line limits the operational envelope to positive nacelle incidence angles only) The rear B-sump scavenge tube was replaced with an extended tube
The forward C-sump scavenge line was removed, and in its place a second $C$-sump aft scavenge line was installed (this also limits operation to positive nacelle incidence only)

The engines were equipped with super pumps and other current TF-34 lubrication system upgrades. Figure 20 illustrates the relative positions of the transfer tanks, sump tank, gearbox, and scavenge lines.

\section{References}

${ }^{1}$ Roberts, L., Deckert, W, and Hickey, D., "Recent Progress in V/STOL Aircraft Technology," NASA TM-81281, 1981

${ }^{2}$ Falarski, M. D., Dudley, M. R., et al, "Aerodynamic Characteristics of a Large-Scale Twin Tilt-Nacelle V/STOL Model," AIAA Paper 81-0150, 1981

${ }^{3}$ Dudley, M, Falarski, M., Pisano, A, and Hill, W, "Ground Effect Hover Characteristics of a Large-Scale Twin Tilt-Nacelle V/STOL Model," AIAA Paper $81-2609,1981$

4"Full-Scale Tests of Grumman Design 698-411 Tilt-Nacelle V/STOL Model at the NASA Ames Research Center," NAVAIR Report N00019-80-C-0115, Dec 1981

${ }^{5}$ Wilson, S, B., et al, "Handling Characteristics of a Simulated Twin Tilt Nacelle V/STOL Aircraft," SAE Paper 831549, Oct 1983

${ }^{6}$ Eskey, M. Wilson, $s$, et al, "Twin Tilt Nacelle V/STOL Aircraft," SAE Paper 841556, Oct 1984

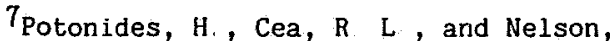
$T$ F , "Design and Experimental Studies of a Type A V/STOL Inlet," AIAA Paper 78-956, 1978.

$8^{8}$ Dudley, M. "Experimental Techniques for Three-Axes Load Cells Used at the National Full Scale Aerodynamic Complex," NASA TM-86693, 1985

${ }^{9} \mathrm{Hall}$, G. R and Rogers, K. H. "Recirculation Effects Produced by a Pair of Heated Jets Impinging on a Ground Plane," NASA CR-1307, 1969 

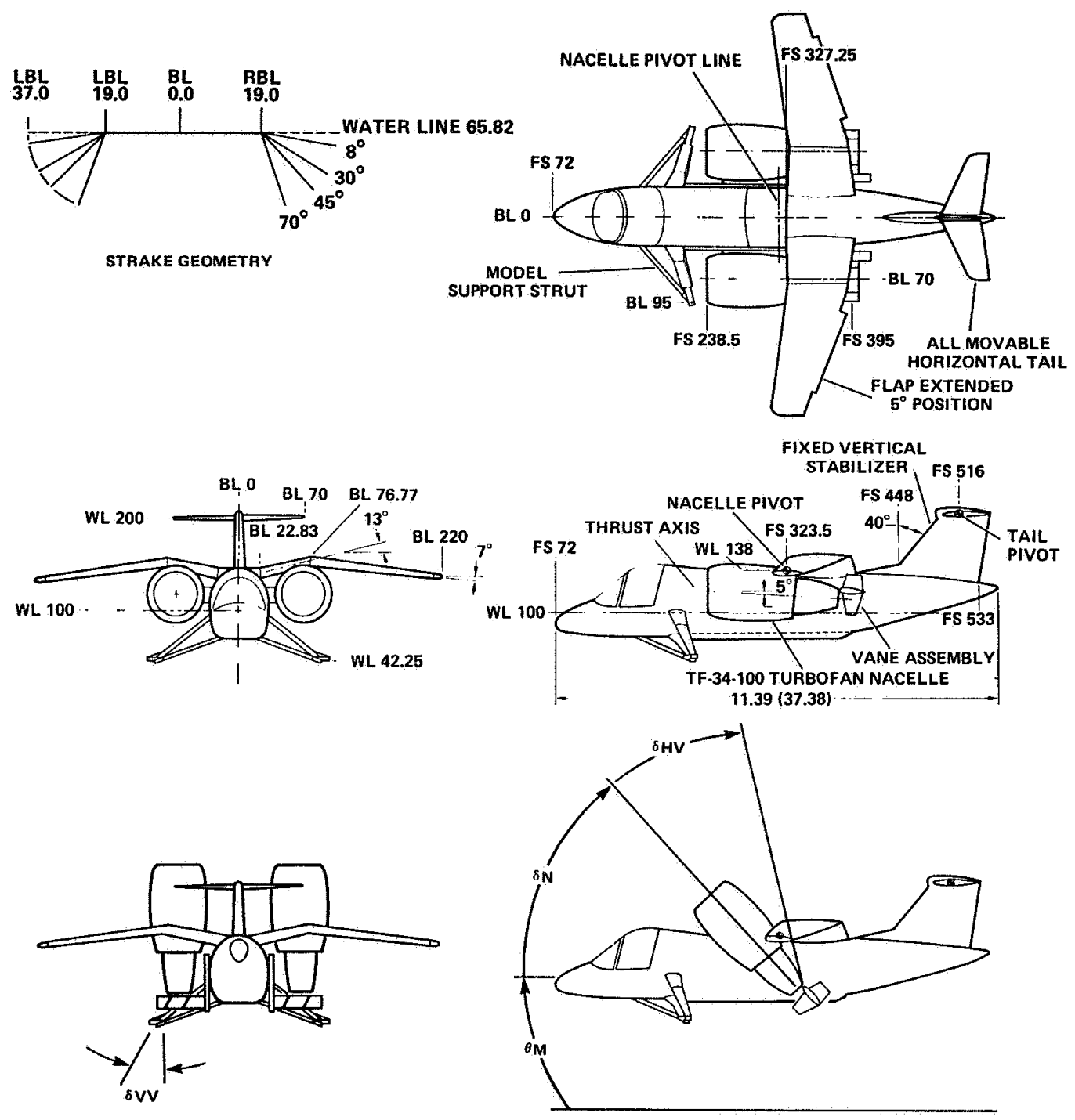

ALL DIMENSIONS IN $m$ (ft)
\begin{tabular}{|l|c|c|c|}
\hline SPAN, $m(f t)$ & WING & $\begin{array}{c}\text { HORIZONTAL } \\
\text { TAIL }\end{array}$ & $\begin{array}{c}\text { VERTICAL } \\
\text { TAIL }\end{array}$ \\
\hline AREA, $m^{2}\left(\mathrm{ft}^{2}\right)$ & $-11.18(36.67)$ & $3.56(11.67)$ & - \\
ASPECT RATIO & $16.44(177)$ & $3.07(33)$ & $3.53(38)$ \\
LEADING EDGE SWEEP, dog & 7.6 & 4.1 & .95 \\
TAPER RATIO & $2.5 /-7.5$ & 25 & 40 \\
DIHEDRAL DEG & 0.466 & 0.489 & .53 \\
AIRFOIL & $0 / 13 /-7$ & 0 & \\
- - & - & NACA $64 A 012$ & NACA $64 A 012$ \\
\hline
\end{tabular}

Fig 1 Model geometry 


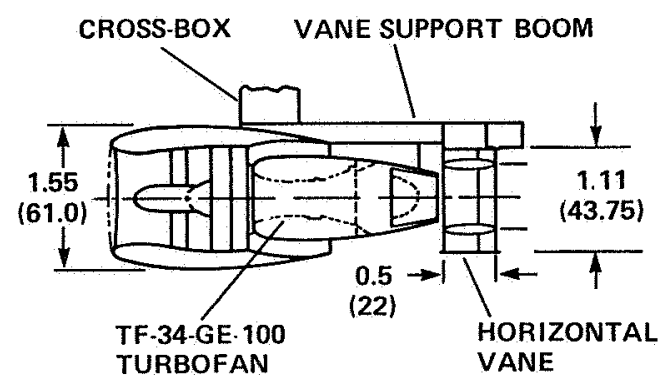

ORIGINAL PAEE- IS

OF POOR OUAUTTY

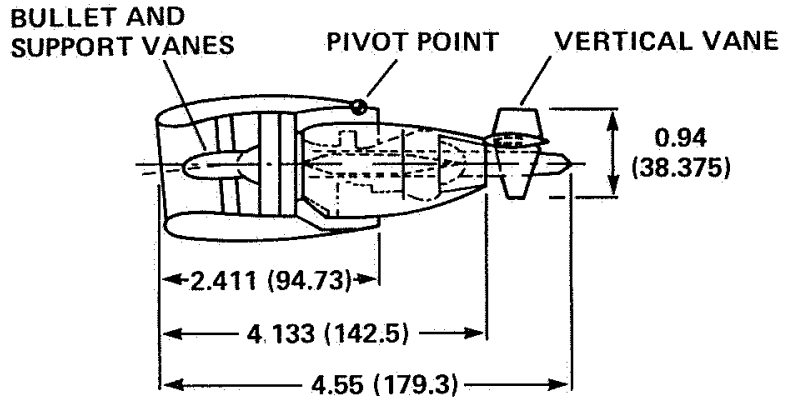

ALL DIMENSIONS IN meters (inches)

Fig 2 Nacelle/dumbbell geometry

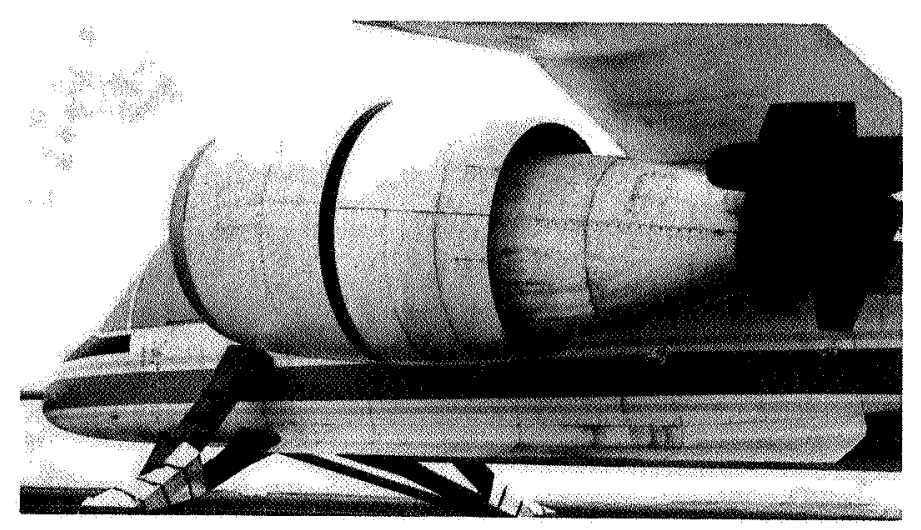

Fig. 3 Control vane installation. 


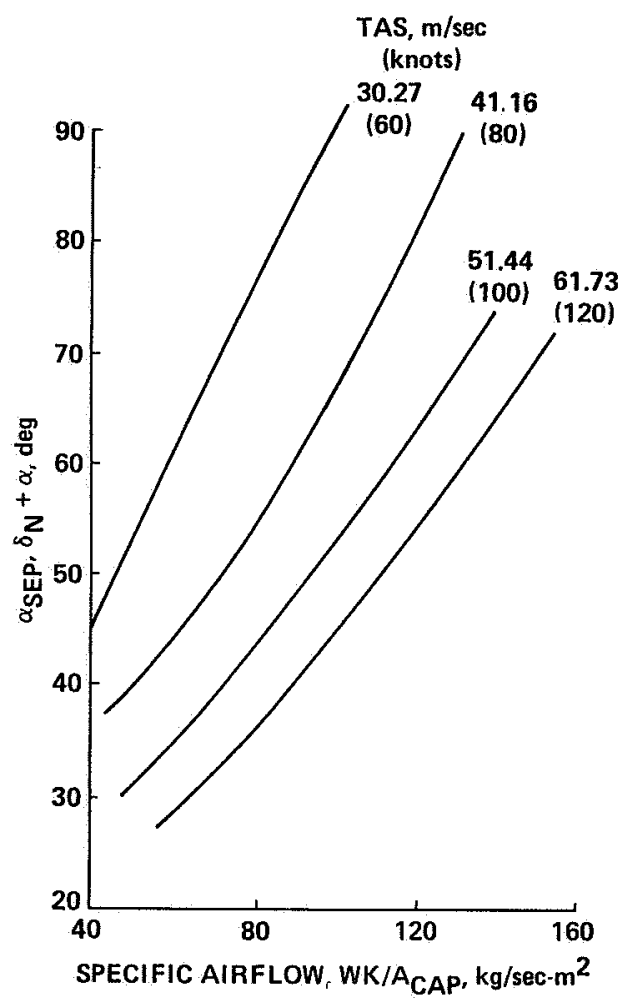

(Reference 4 pp 226 to 230)

Fig. 4 Inlet separation boundaries 


\section{ORIGINAL PACE IS \\ OF POOR QUALTTY}

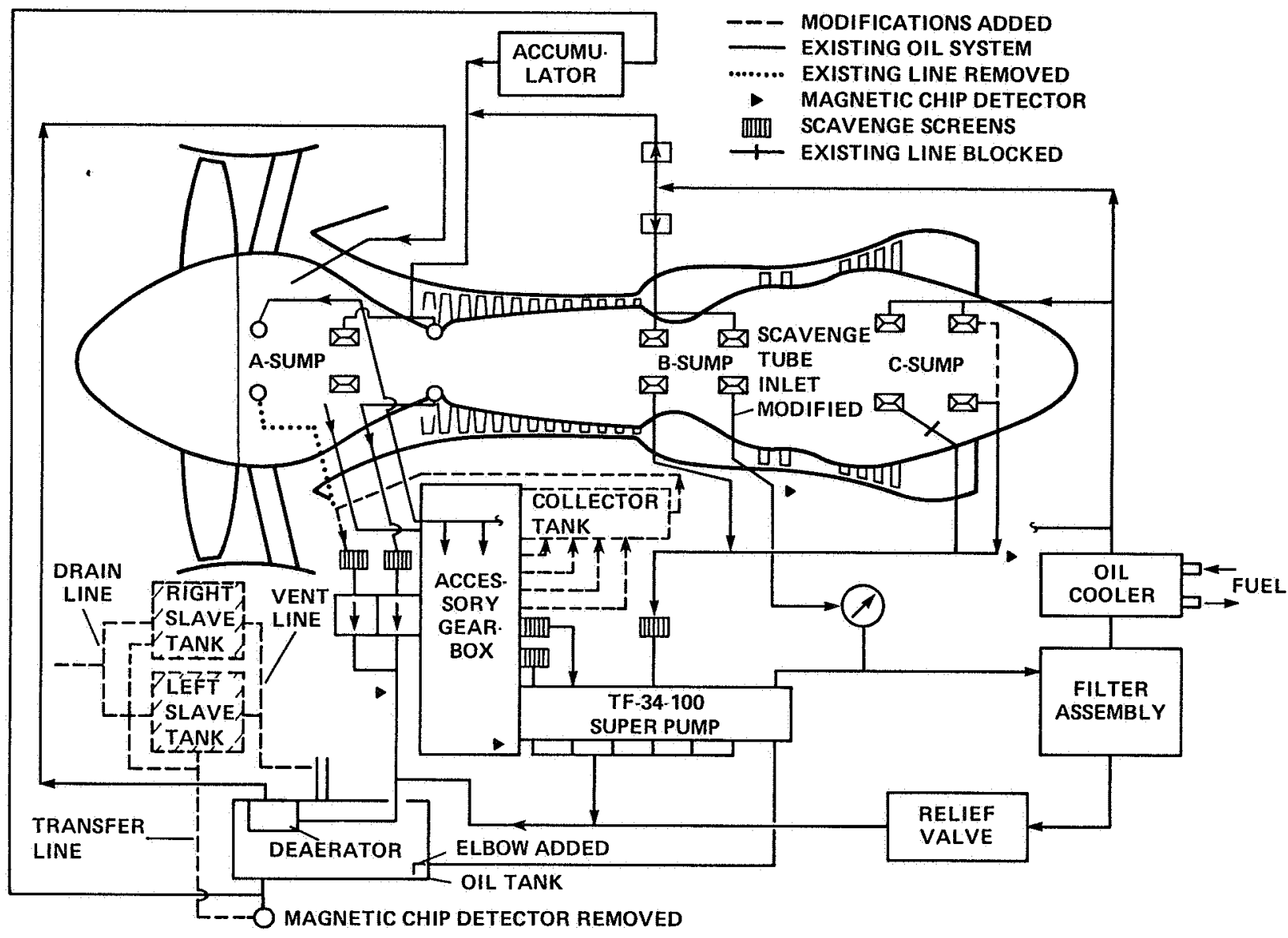

Fig $5 \mathrm{TF}-34$ lube system and modifications.
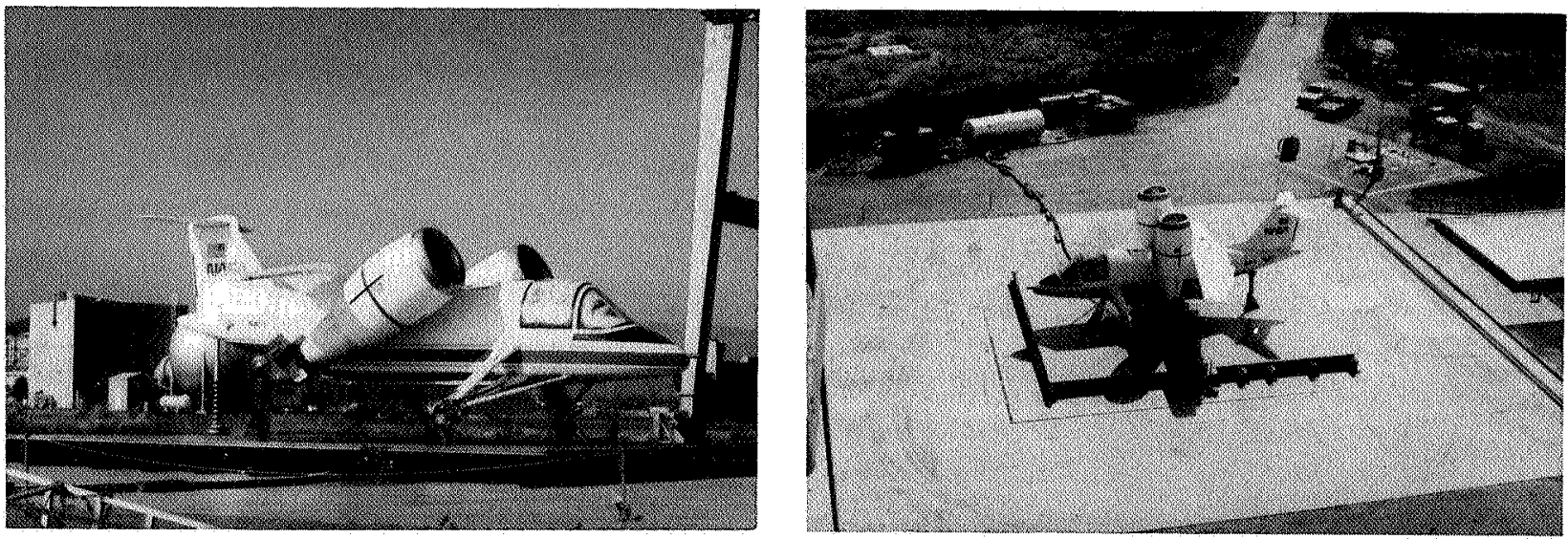

Fig 6 Two views of model installation 


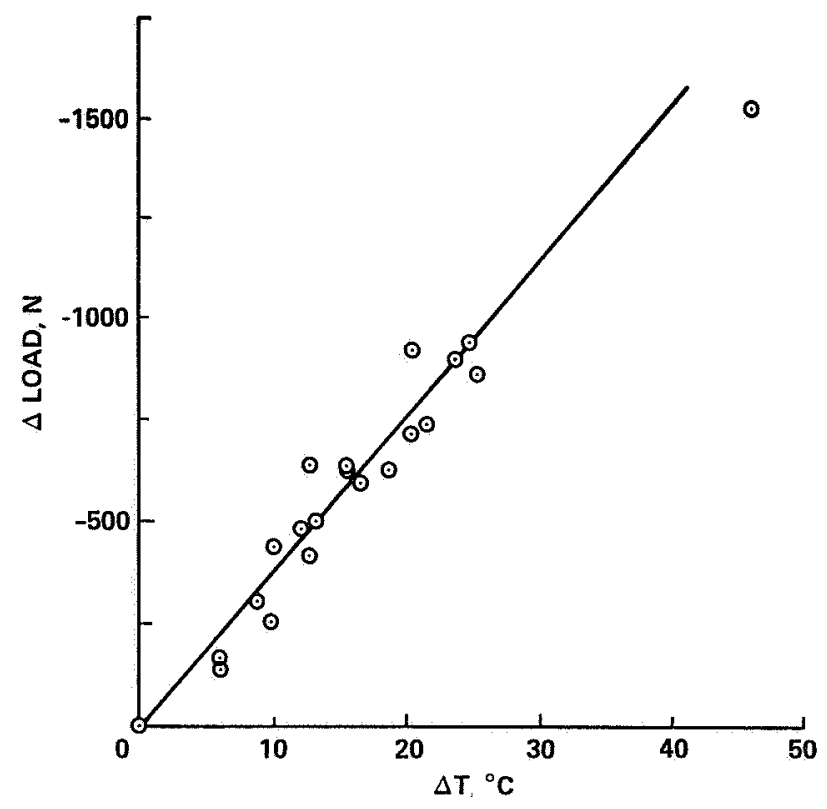

Fig 7 Tail strut normal force thermal correction.

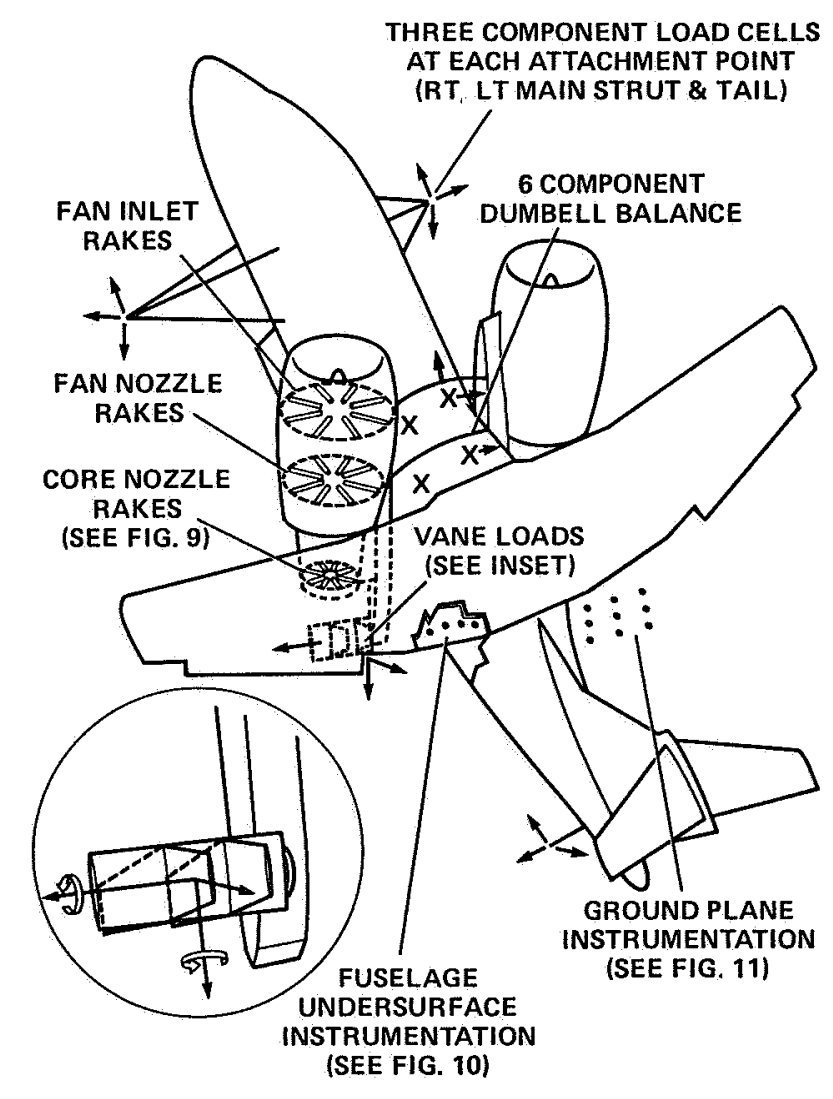

Fig 8 Instrumentation layout. 


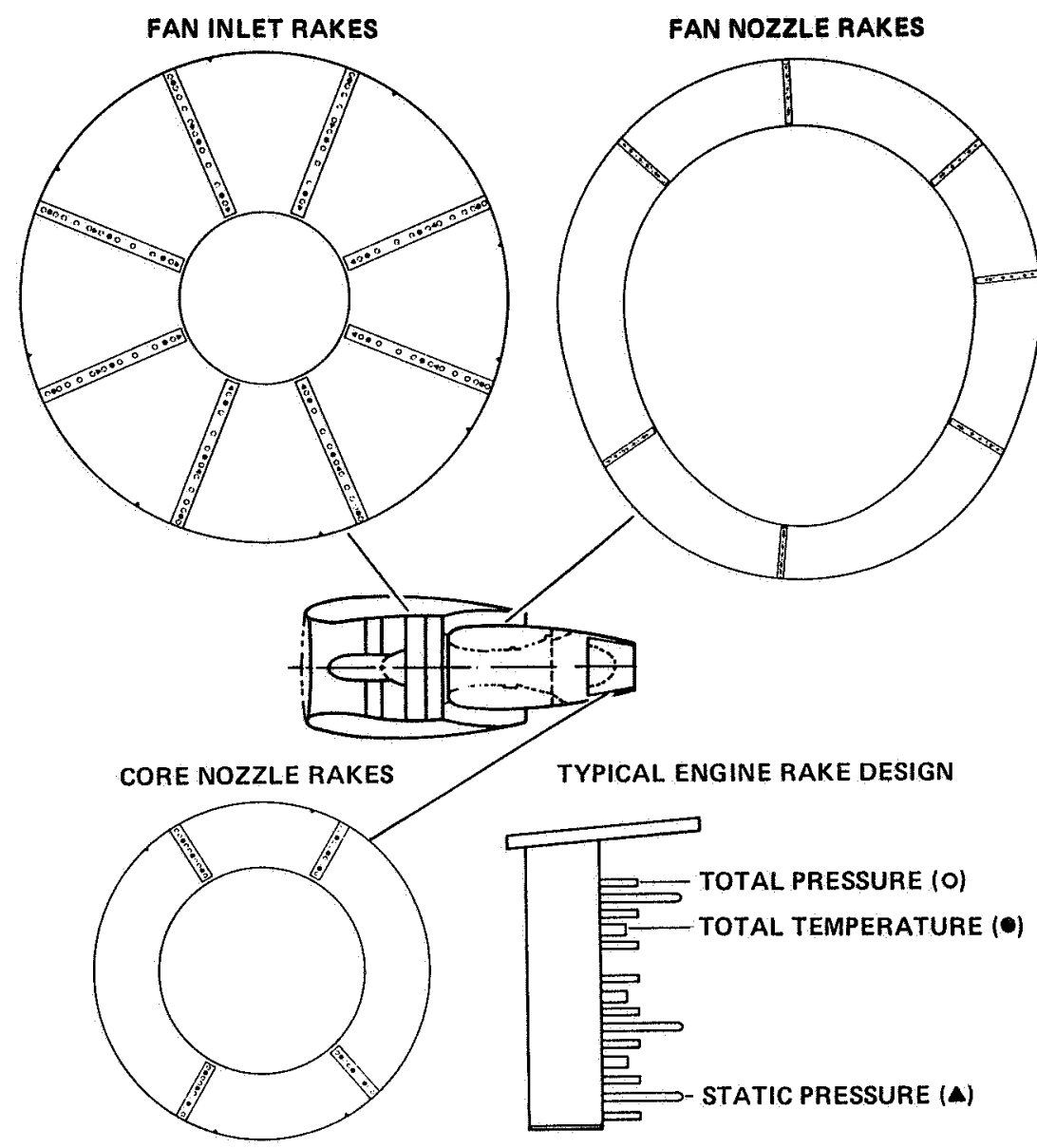

Fig 9 Left engine airflow instrumentation



Fig, 10 Fuselage undersurface instrumentation and strake geometry 




Eig 11 Ground plane instrumentation

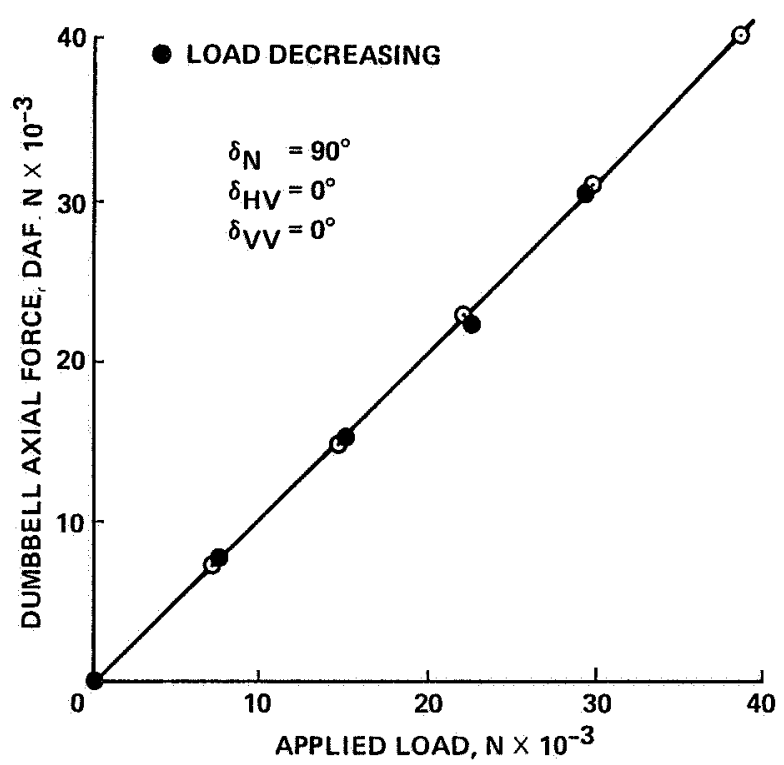

Fig 12 Typical dumbbell balance calibration

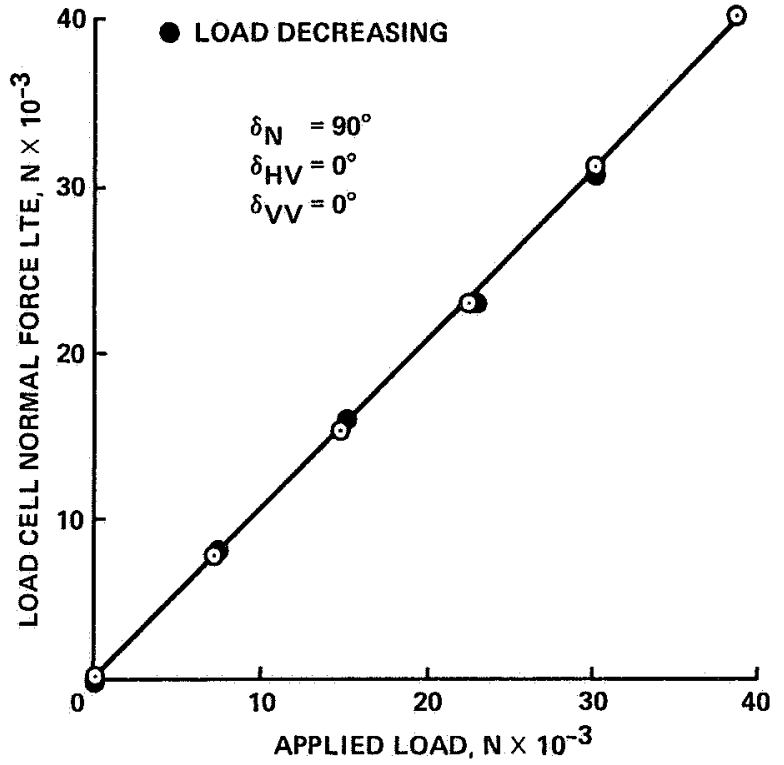

Fig. 13 Typical main load cell calibration 

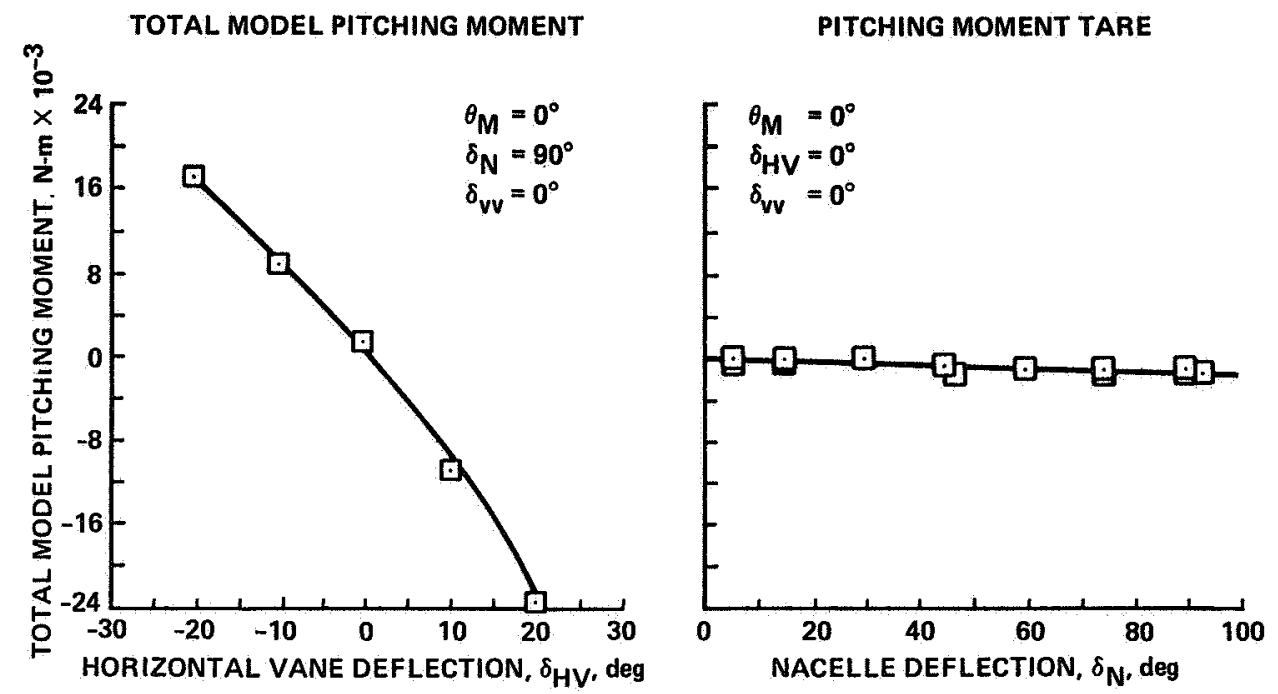

Fig. 14 Comparison of model pitching-moment tare with typical pitching-moment data.

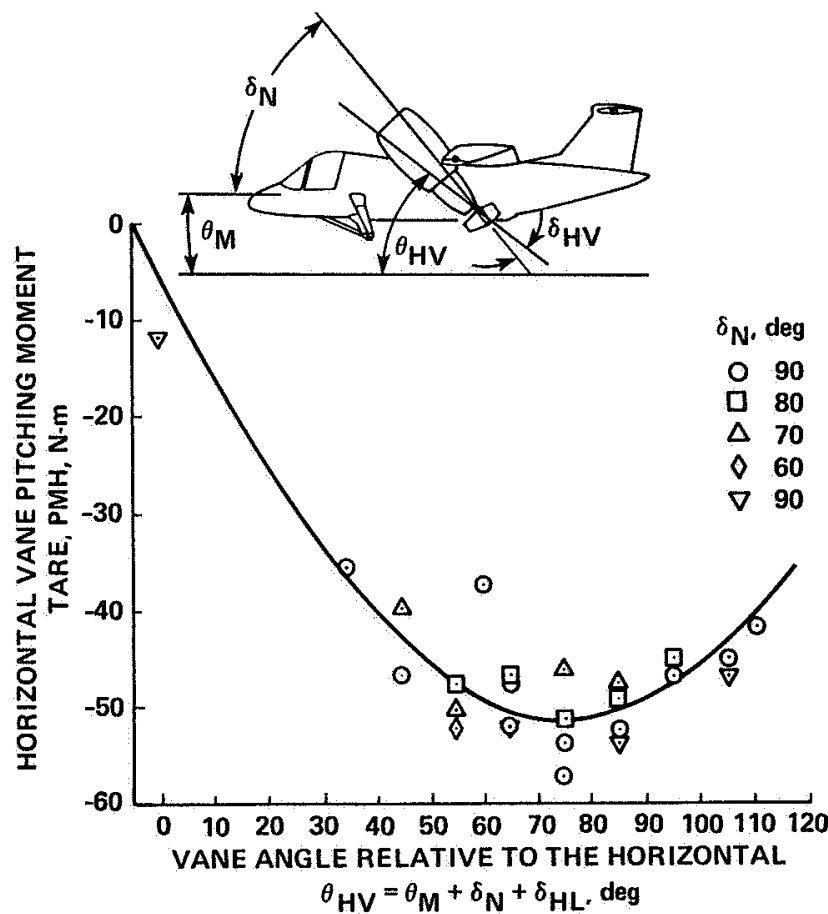

Fig 15 Horizontal-vane pitching-moment tare.

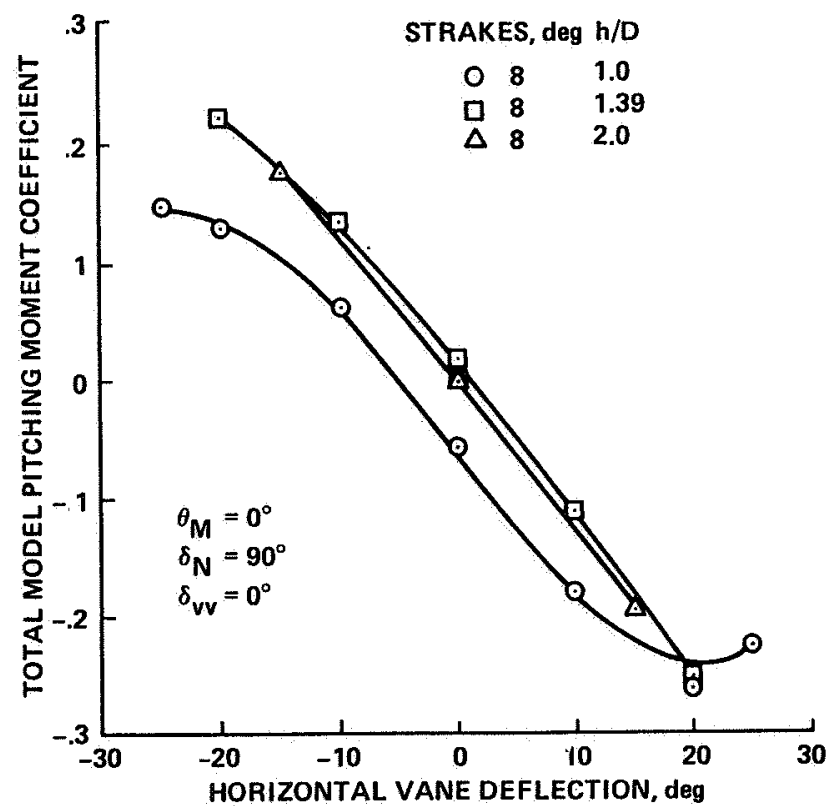

Fig. 16 Total model pitching-moment coefficient versus horizontal-vane deflection at various heights. 


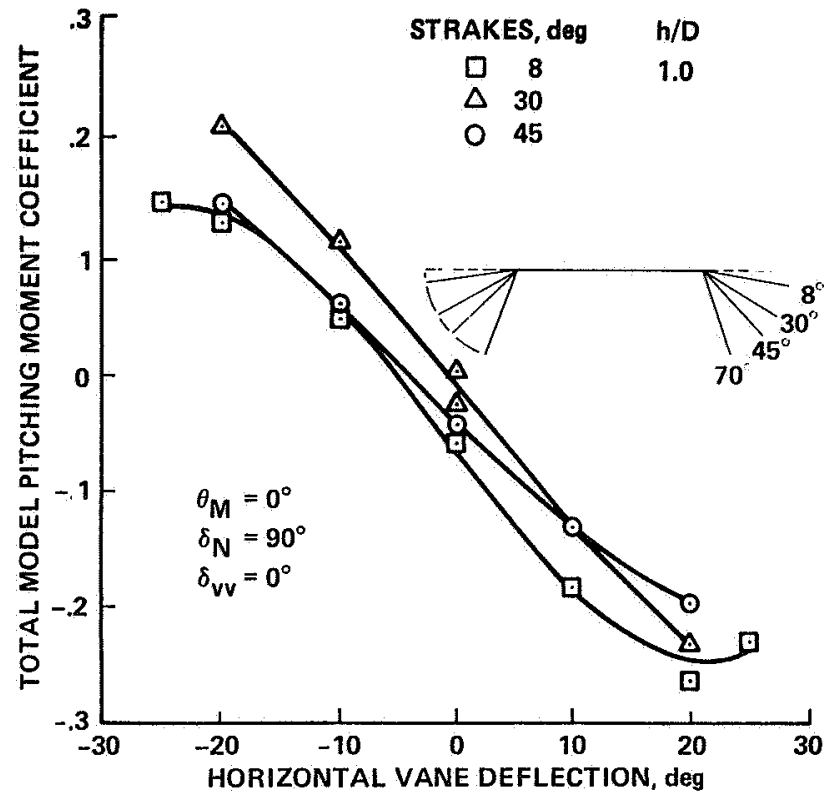

Fig. 17 Total model pitching-moment coefficient versus horizontal-vane deflection for various strake angles



HEIGHT OF FUSELAGE BOTTOM ABOVE GROUND, h/D

Fig 18 Model normal force ratio versus height above ground for various strake deflections.

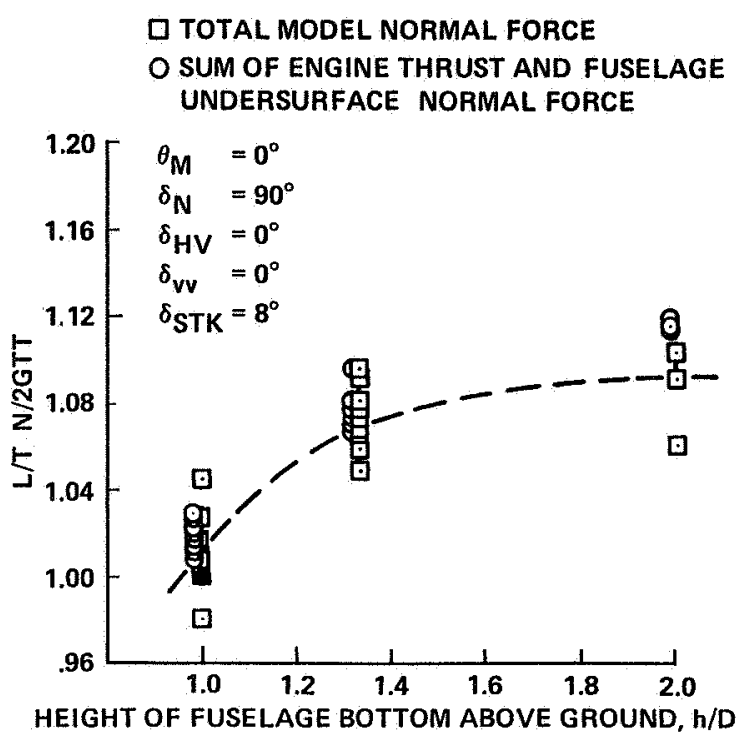

Fig. 19 Comparison of total model normal force with sum of engine thrust and fuselage undersurface normal force.

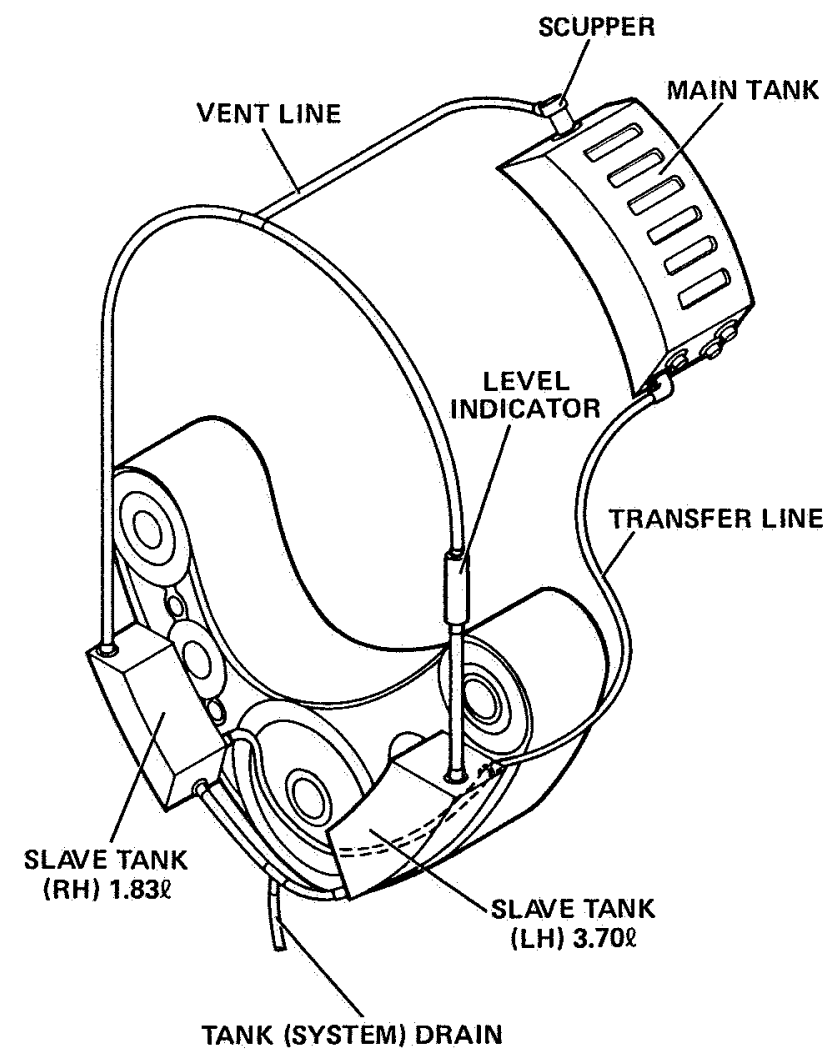

Fig 20 Relative position of lube system components 


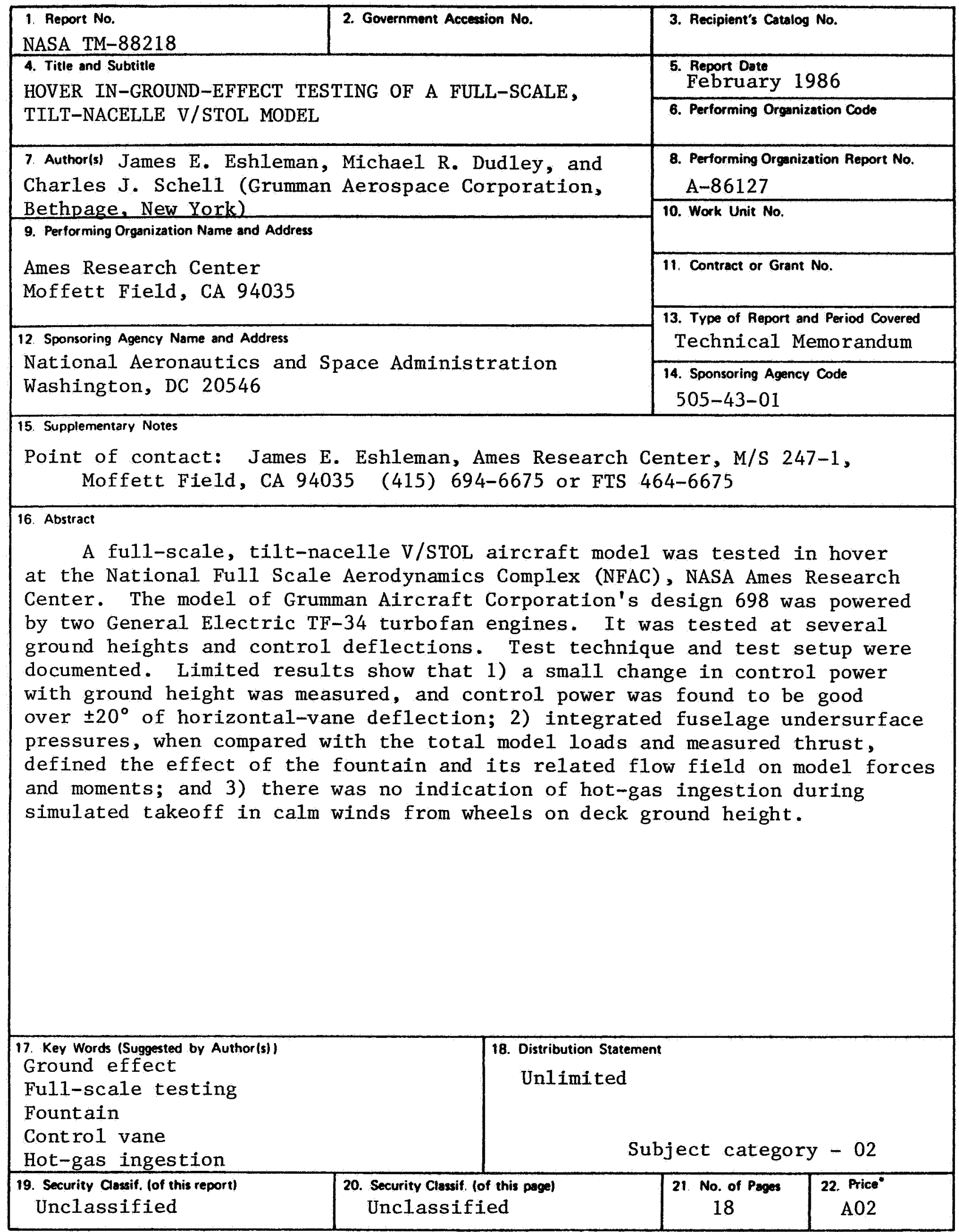

- For sale by the National Technical Information Service, Springfield, Virginia 22161 